\title{
The Predictive Power of Emotional Intelligence in Cyberbullying among Jordanian University Students
}

\author{
Khaled Al-Sarayra ${ }^{1}$ \\ ${ }^{1}$ Psychology and Especial Education Department, Al-Balqa Univeristy, Jordan \\ Correspondence: Khaled Al-Sarayra, Psychology and Especial Education Department, Al-Balqa Univeristy, \\ Jordan. E-mail: Khaled.alsarayreh@bah.edu.jo
}

Received: June 26, 2021 Accepted: January 13, 2022 Online Published: January 25, 2022

doi:10.5539/jedp.v12n1p31

URL: http://doi.org/10.5539/jedp.v12n1p31

\begin{abstract}
The present study aimed to identify the predictive power of emotional intelligence in cyber violence among Jordanian university students. The researcher constructed the Cyber Violence Scale and translated the Emotional Intelligence Scale developed by Richa Jain (2015). Both scales had the appropriate indices of validity and reliability. The study sample consisted of 444 university students who participated from eight different courses to fulfill the requirements of the general college at Al-Balqa' Applied University in Jordan during the first semester of the 2016-2017 academic year. After collecting and analyzing the data, the following results emerged:

1) The calculated mean of cyber violence among students of Al-Balqa' Applied University was 2.74 with a standard deviation of 1.32, which indicates that the level of cyber violence is in the moderate range.

2) The overall level of emotional intelligence as well as the secondary dimensions of emotional intelligence (social skills, self-awareness, self-motivation, emotional regulation, empathy) were in the high range among students of Al-Balqa' Applied University.
\end{abstract}

3) There was a negative correlation between the overall level of emotional intelligence dimensions as well as the secondary dimensions of emotional intelligence (self-awareness, emotional regulation, self-motivation, empathy, social skills) and cyber violence.

4) Emotional intelligence dimensions accounted for $18 \%$ of cyber violence. Self-motivation and emotional regulation were the two most significant predictors of cyber violence.

Keywords: emotional intelligence, college, cyberbullying, students, university

\section{Background and Theoretical Framework}

Technology is considered one of the most prominent human creative activities of the 20th century, alongside various scientific advancements. Technology has invaded all aspects of life, and whoever owns technology has great power and control. The world has witnessed tremendous developments in the field of information technology within various fields in the last century, from means of communication to the speed of circulation and information exchange around the world, in addition to tremendous social developments. The pace of life has accelerated in all aspects, and questions have been raised about what might accompany this enormous revolution in terms of the negative effects on human beings, who are at the center of every process of progress and prosperity. Technology is the application of scientific principles, and like any application process, it can be a double-edged sword. Despite the blessings and civilizational benefits of technological achievements, there are many who misuse it. The increasing use of information technology in everyday life has led to growing concerns regarding the negative side effects, especially among adolescents and young people, who are at risk of being exposed to abuse and aggression.

Social networks, such as Facebook, are online platforms that connect millions of people who share common interests. These networks allow users to share files, pictures, and videos, create blogs, send messages, and hold instant conversations with one another. Global statistics highlight a growing demand for social networks around the world, and according to these statistics, Jordan ranked high at the Arab and global levels in the list of countries with the highest level of engagement on Facebook. This is after the Facebook subscription base in the country was estimated at about two million subscribers at the end of 2011, while the total number of Internet users exceeded 2.7 million users (Nejadat, 2014). 
The modern world is witnessing a massive cognitive and technological revolution, a revolution that has resulted in the emergence of many modern technologies that saved people a lot of time and effort. And despite the positive aspects of these technologies, they have nevertheless created many forms of strange behaviors and practices, which might not have existed without the emergence of such technologies. The technological changes that the world has witnessed, and the consequent tremendous evolution of communication means and the presence of many modern technologies, has resulted in the emergence of a new type of crime, which differs greatly in its form, means, and perpetrators, from the traditional concept of crime. This is what is termed "cybercrime," the danger of which increases - especially with the increasing number of users of these technologies - day after day.

The technological and cognitive revolution we are witnessing today, the continuous social, political, and cognitive changes and challenges, and the multiplicity of interests, emphasize the important role of the university in determining outputs that are compatible with the nature of this era, and the employment of the university's mission in basic functions, such as preparing human resources, conducting scientific research, and contributing to the process of upbringing and knowledge transfer in a manner that supports building and shaping student awareness, addressing community issues and problems, and working to serve and develop society in all its political, economic, cognitive, and social aspects (Bakir, 2010; Fonseca \& Nieth, 2021).

Cyber violence occurs through the use of electronic technology through the internet. Technology includes electronic devices and equipment, such as cell phones, computers, and tablets (iPads), as well as communication tools including social networking sites, text messages, whether through the iPhone, computer, laptop, video tapes, chat rooms, or other sites. Manifestations of violence are always present on this network, 24 hours day and night, where individuals can explore this network on their own without supervision, particularly children. Images and messages are published by anonymous people at a high speed, and it is difficult to trace the source of these files and to delete them as well. Although cell phones and computers are not responsible for spreading violent scenes - as social networking sites can be used for social activities, such as connecting children with family and friends, helping them study, and providing entertainment - however, these devices and sites can cause harm, whether they are used by an individual or accessed through the internet. Research shows that the impacts of cyber violence are similar to the negative impacts of exposure to real-life violence, which include alcohol and drug abuse, mental absence or escapism, learning about violence and criminality from virtual criminals, an unwillingness to get out of the house, low student educational achievement, poor self-esteem and self-confidence, and physical illness (Sebti, 2013; Backe Lilleston \& McCleary-Sills, 2018; Holdren, 2020).

This is where the importance of emotional intelligence emerges, as we find that society is facing many political, social, cultural, and economic problems. There is no doubt that the solutions to most of these problems that cause distress and anxiety to the community is for the individual to possess well-developed intellectual abilities, as well as social and emotional skills that complement intellectual skills to solve the present problems. This highlights the importance of having people skills and effective harmony with others, and this has all contributed to the interest in emotional intelligence (Pfeiffer, 2001).

In other words, we must pay attention to the emotional aspects of the individual, considering that it is one of the means of adaptation to the successive and conflicting variables surrounding him/her, since feelings and emotions are one of the most important influences in guiding the individual's behavior in general and way of thinking, issuing judgments, and making decisions, in particular. The emotional state of an individual, whether that includes feelings of sadness, joy, anger, or hostility, greatly influences the way he/she deals with and manages life matters, especially at the university level, considering that university students are at a stage where they are searching for identity, self-affirmation, and openness to life in a way that may initially be irrational, characterized by foggy judgment and an incomplete comprehension of life matters (Trigueros et al., 2020).

\subsection{Research Questions}

The current study addresses the predictive ability of emotional intelligence in cyber violence among Jordanian university students, which can be determined by answering the following questions:

- What is the level of cyber violence among Jordanian university students?

- What is the level of emotional intelligence among Jordanian university students?

- Is there a significant correlation between cyber violence and emotional intelligence dimensions among Jordanian university students?

- Which emotional intelligence dimensions are the most predictive of cyber violence among Jordanian university students? 


\subsection{Research Significance}

The research study draws attention to the issue of cyber violence and emotional intelligence among university students, on the basis that violence is a behavior that is accompanied by specific emotions that are characterized by a strong sense of dissatisfaction in humans, and that emotional intelligence has varying effects on one's personality in all its aspects. Its importance also stems from the need to shed light on this type of violence, which carries numerous negative consequences that threaten the security and safety of society. Further, the importance of the study stems from the activation of the role of the university and its contributions to solving one of the significant issues that society currently faces, and it may hold benefits for many sectors, institutions, and entities of the university.

\subsection{Procedural Definitions}

\subsubsection{Cyber Violence}

Violence that occurs through the use of electronic technology through the internet is referred to as cyber violence. This includes electronic devices and equipment, such as mobile phones, computers, tablets (iPads), as well as communication platforms including social networking sites and text messages delivered through an iPhone, computer, laptop, video tapes, chat rooms, and other sites (Sebti, 2014).

Cyber violence is defined in legal dictionaries as follows: acts that use technology and communication information to support intentional, repeated, and hostile behavior by an individual or a group with the aim of harming others (Sebti, 2014). It is defined in procedural terms as the total degree obtained by the respondent on the cyber violence scale used in the study.

\subsubsection{Emotional Intelligence}

The concept of emotional intelligence refers to the ability to accurately perceive, regulate, and express emotions, as well as the ability to generate and access emotions during the thinking process, the ability to understand the emotion and the underlying emotional knowledge, and the ability to organize emotions in a way that promotes the emotional and mental growth of the individual (Mayer \& Salovy, 2007). It is procedurally defined in this study as the overall degree obtained by a respondent on the emotional intelligence scale used in the study.

\subsection{Study Parameters}

The results of the study shall be determined by the participants included in the study in the governorate of Amman. The results of the study shall also be determined by the scales used in the study and the resulting indices of validity and reliability of the students' performance.

\subsection{Previous Studies}

The Novo, Pereira, and Matos' (2015) study, titled "Cyber-Aggression among Portuguese Adolescents: A Study on Perpetration, Victim Offender Overlap and Parental Supervision", aimed to study the dark side of cyber communication among adolescents; specifically, the frequency of the perpetrations of aggression (cyber-stalking) and the overlap between victimisation, the offender, and parental supervision. The study conducted a survey of the views of 627 adolescents (12-16 years) and 586 parents. The results indicated a worrisome frequency of cyber attacks, and they demonstrated a high overlap between victims and offenders and the influence that parents have on their adolescent children's aggressive behavior in the virtual environment. Further, the study by Vale and colleagues (2018) titled "Cyber-aggression in adolescence and internet parenting styles: A study with victims, perpetrators and victim-perpetrators" examined the relationship between cyber aggression among adolescents and parenting styles. Adolescents who used technology more frequently and had permissive parenting styles were more likely to be involved as victim-perpetrators.

A more recent study by Martinez-Monteagudo and colleagues (2019) titled "Cyberbullying in the university setting; relationship with family environment and emotional intelligence", examined the predictive capacity of family environment and emotional intelligence in cyberbullying behaviors among a sample of 1282 Spanish university students. Results showed that a deteriorated family environment is correlated with a higher likelihood of becoming both a victim and perpetrator of cyberbullying. Moreover, the study revealed that dimensions of emotional intelligence predicted participation in cyberbullying as both a victim and perpetrator. Specifically, it indicated that low emotional regulation and high excessive attention to one's feelings increases the probability of being a victim of cyberbullying, while low emotional understanding increases the probability of being a perpetrator.

The Jarrar (2011) study, titled "Participation on Facebook and its Relationship with the Attitudes of Jordanian University Students towards Family Relations", aimed to learn about participation on Facebook and its 
relationship with young people's attitudes towards family relations, considering that the nature of the relationship between young people and their families is one of the most important indicators of the nature of their interaction with their real society, and the fact that the family is one of the most important pillars for the inheritance and continuation of cultural autonomy. The researcher used a descriptive methodology, and a questionnaire was used to collect data. The study's target participants were young people between 15-24 years old in Jordan, with the selected sample consisting of 384 young men and women between $15-24$ years old. The results showed that $74.4 \%$ of Jordanian youth participate in Facebook, and that the percent of participating males (56\%) is greater than the percent of participating females (44\%). Results also indicated that nearly three-quarters of the participants check Facebook daily (73.8\%), more than half of young subscribers $(57.4 \%)$ believe that their participation reduces the time they spend with their families, $45.6 \%$ saw that their participation in the site has had a positive impact on their lives, and $14.2 \%$ couldn't determine whether or not their participation in the site affected their lives.

The Al-Masri study (2011), titled "The Use of Social Networking Sites by University Students and their Impact on Other Media Outlets", aimed to determine the extent to which Palestinian university students use social networking sites, and its impact on their usage of other media outlets. The study also aimed to identify the negative and positive effects of the students' use of these sites using a sample of 50 Palestinian college students in Gaza. The study found that $52 \%$ of participants use social networking sites for up to two hours a day. The study also indicated that the most significant negative effects of using social networking sites are the fueling of political crises, providing an opportunity for recruitment by others, increasing hatred and deepening differences, at a level of $78 \%$. The most significant positive effect was introducing users to topics that would help them engage in discussions with others at a level of $47 \%$. As for the impact of using social networking sites on other media and communication outlets, the study showed a notable decline in reading books, reading newspapers and magazines, listening to the radio, and watching satellite channels, at levels ranging from $76 \%$ to $84 \%$.

The Barakat study (2009), titled "The Various Negative Effects of Modern Means of Communication on Social Upbringing", aimed to identify the negative effects of satellite channels, the internet, mobile phones and modern means of communication on social upbringing. It also aimed to identify the role of the family and school in limiting these effects. The study found that the internet has some negative effects, such as skepticism about scientific information, internet cafes that allow access to banned and pornographic sites in order to increase the number of visitors, and chat rooms that provide a space for discussion and freedom of expression, which young people consider to be one of the most important ways to meet and sometimes build unhealthy social relationships. As for the mobile phone, negative effects include using the phone while driving and using it as a tool for spreading corruption and immoral scenes that go against public morality and social mannerisms. The study made some suggestions about the role that social institutions can perform in the community.

A study by Extremera and colleagues (2018) titled "Cyberbullying Victimization, Self-Esteem and Suicidal Ideation in Adolescence: Does Emotional Intelligence Play a Buffering Role?" examined the role of emotional intelligence in protecting against the negative psychological impacts of cyberbullying, such as suicidal ideation and low self-esteem, among victims in a sample of 1660 Spanish adolescents. The study found that adolescents with high emotional intelligence experienced lower levels of suicidal ideation and higher self-esteem compared to those with lower emotional intelligence. Another study of 490 Indian university students revealed a negative relationship between spirituality and cyberbullying, which was mediated by emotional intelligence dimensions, including appraisal of self-emotions, appraisal of other's emotions, and emotion regulation (Yadav \& Yadav, 2018).

The Golubev study (2009), "Criminals in Computer-related Crimes", aimed to identify the motives of computer criminals. The study found that these motives consist of the following: $66 \%$ have spying-related motives, $17 \%$ are politically motivated, $7 \%$ are research curious, and $5 \%$ have motives related to viewing sexual sites. The study showed that $33 \%$ are under 20 years of age, $45 \%$ are between 20 and 40 years old, and $13 \%$ are over 40 years of age, which indicates that the majority are between 13 and 20 years of age. The study also showed that the number of criminals multiplies by five times annually, and that $7.5 \%$ have high technical capabilities, especially those who work in fields related to accounting, secretarial jobs, management, and others.

The Ateya study (2007), "An Experiment in the Ethics of the Information Society", aimed at surveying the views of the study sample on the ethics of the information society. The findings highlighted the need for charters that govern professional work, and it demonstrated the contradiction between the articles of the ethics document developed by the American Library Association. Further, it indicated that any ethics-related document must be based on family values and the ethics of the society it serves in order to prevent contradictions between the representation of professional principles and social values. 


\subsection{Comment on Previous Studies}

Based on previous studies, it is clear that there is an interest in cyber violence, both locally and globally, and as there are few studies that have addressed the relationship between cyber violence and emotional intelligence, the present study differs from previous studies in that it attempts to determine the predictive ability of emotional intelligence in cyber violence.

\section{Methods and Procedures}

\subsection{Study Methodology}

The descriptive relational methodology was used to achieve the objectives of the present study, as this approach is the most appropriate for the study's objectives. The present study aims to determine the predictive ability of emotional intelligence in cyber violence among students at the Al-Balqa' Applied University.

\subsection{Study Population and Sample}

The study population will consist of all students at the Al-Balqa' Applied University who are currently studying at the University College of Princess Alia. The study sample was selected from eight different courses for the requirements of the general college. The number of students in the study sample was 444 males and females ranging from the first to fourth years of study, completing the first semester of the academic year 2016-17. Table 1 shows the distribution of the study sample by sex, college, and education level.

Table 1. Distribution of Study Sample by Sex, College, and Education Level

\begin{tabular}{|c|c|c|c|}
\hline & & Frequency & Percent (\%) \\
\hline \multirow{3}{*}{ Sex } & Male & 172 & 38.7 \\
\hline & Female & 272 & 61.3 \\
\hline & Total & 444 & 100.0 \\
\hline \multirow{3}{*}{ College } & Science & 268 & 60.4 \\
\hline & Humanities & 176 & 39.6 \\
\hline & Total & 444 & 100.0 \\
\hline \multirow{5}{*}{$\begin{array}{l}\text { Education Level (year of } \\
\text { study) }\end{array}$} & First & 59 & 13.3 \\
\hline & Second & 187 & 42.1 \\
\hline & Third & 172 & 38.7 \\
\hline & Fourth & 26 & 5.9 \\
\hline & Total & 444 & 100.0 \\
\hline
\end{tabular}

\subsection{Study Tools}

Two tools have been constructed to achieve the objectives of the current study: the first is a scale for measuring the degree of cyberbullying, and the second is for emotional intelligence. The following steps were taken to construct both tools:

1) Review of previous literature and scales regarding cyberbullying and emotional intelligence.

2) Preparation of the two study scales in an initial format for the purpose of presenting them to the panel of experts.

3) Using the arbitrators' feedback to produce the finalized version of the scales.

\subsubsection{The Cyberbullying Scale}

The cyberbullying scale is made up of 17 items that measure behaviors related to threats, blackmail, and libel that are practiced by social media and internet users. The items are rated on a 5-level scale ('Strongly Agree' is 5 points, 'Agree' is 4 points, 'Neutral' is 3 points, 'Disagree' is 2 points, and 'Strongly Disagree' is 1 point). Thus, the overall score ranges from 17 to 85 points, where a higher score indicates practicing cyberbullying to a higher degree.

To verify the validity of the cyberbullying scale, it was presented to 10 arbitrators specializing in the fields of 
psychology, mental health, and psychological counseling, in order to judge the validity of the scale items in the light of the concept and definition of cyberbullying. Based on the criteria of clarity and the item statements' affiliation with the behavioral area being measured, which specifically deals with the concept of cyberbullying, the judges expressed several observations regarding the wording of certain statements, which were reformulated, where an $80 \%$ agreement rate was adopted to keep or remove a statement.

The correlation between each statement and the overall score of the scale's statements was also calculated. Table 2 shows the results. As shown in Table 2, we note that all statements were correlated to the overall score at a value higher than 0.30 , indicating that they have a high degree of internal validity.

Table 2. The Correlation Coefficient between Statements and the Overall Score on the Cyberbullying Scale

\begin{tabular}{llll}
\hline Statement & Correlation Coefficient & Statement & Correlation Coefficient \\
\hline 1 & 0.93 & 10 & 0.89 \\
2 & 0.92 & 11 & 0.92 \\
3 & 0.90 & 12 & 0.93 \\
4 & 0.90 & 13 & 0.88 \\
5 & 0.92 & 14 & 0.87 \\
6 & 0.93 & 15 & 0.81 \\
7 & 0.81 & 16 & 0.90 \\
8 & 0.93 & 17 & 0.90 \\
9 & 0.91 & & \\
\hline
\end{tabular}

In order to ascertain the reliability of the scale, the Alpha Cronbach formula was used to calculate the internal consistency of the scale, which was 0.88 . This factor indicates an appropriate level of reliability for the purposes of the present study.

\subsubsection{The Emotional Intelligence Scale}

The emotional intelligence scale consists of 50 items that measure the behaviors and attitudes associated with the elements and dimensions of emotional intelligence. Each item is rated on a five-level scale ('Strongly Agree' is 5 points, 'Agree' is 4 points, 'Neutral' is 3 points, 'Disagree' is 2 points, and 'Strongly Disagree' is 1 point). Thus, the overall score on the scale ranges from 40-200, where a higher score indicates a higher level of emotional intelligence. The items are distributed according to the following:
1) Social skills; measured by 10 items
2) Self-awareness; measured by 10 items
3) Self-motivation; measured by 10 items
4) Emotional regulation; measured by 10 items
5) Empathy; measured by 10 items

The correlation of the scale's item statements with the scale's overall score was also calculated. Table 3 shows the results. As shown in Table 3, we note that all statements were correlated to the overall score at a value higher than 0.30 , indicating that they have a high degree of internal validity. 
Table 3. The Correlation Coefficient between Statements and the Overall Score on the Emotional Intelligence Scale

\begin{tabular}{llllllllll}
\hline \multicolumn{2}{l}{ Social skills } & \multicolumn{2}{l}{ Self-awareness } & \multicolumn{2}{l}{ Self-motivation } & \multicolumn{2}{c}{ Emotional regulation } & Empathy \\
\hline $\begin{array}{l}\text { Statement } \\
\text { Correlation } \\
\text { Coefficient }\end{array}$ & Statement & $\begin{array}{c}\text { Correlation } \\
\text { Coefficient }\end{array}$ & Statement & $\begin{array}{c}\text { Correlation } \\
\text { Coefficient }\end{array}$ & Statement & $\begin{array}{c}\text { Correlation } \\
\text { Coefficient }\end{array}$ & Statement & $\begin{array}{c}\text { Correlation } \\
\text { Coefficient }\end{array}$ \\
\hline 1 & 0.62 & 11 & 0.59 & 21 & 0.54 & 31 & 0.69 & 41 & 0.52 \\
2 & 0.55 & 12 & 0.59 & 22 & 0.54 & 32 & 0.65 & 42 & 0.51 \\
3 & 0.57 & 13 & 0.65 & 23 & 0.52 & 33 & 0.66 & 43 & 0.50 \\
4 & 0.52 & 14 & 0.56 & 24 & 0.68 & 34 & 0.53 & 44 & 0.38 \\
5 & 0.63 & 15 & 0.58 & 25 & 0.64 & 35 & 0.43 & 45 & 0.53 \\
6 & 0.49 & 16 & 0.69 & 26 & 0.66 & 36 & 0.48 & 46 & 0.63 \\
7 & 0.64 & 17 & 0.64 & 27 & 0.58 & 37 & 0.43 & 47 & 0.64 \\
8 & 0.58 & 18 & 0.67 & 28 & 0.67 & 38 & 0.53 & 48 & 0.60 \\
9 & 0.63 & 19 & 0.50 & 29 & 0.69 & 39 & 0.49 & 49 & 0.62 \\
10 & 0.60 & 20 & 0.52 & 30 & 0.52 & 40 & 0.30 & 50 & 0.52 \\
\hline
\end{tabular}

To verify the validity of the emotional intelligence scale, it was presented to 10 arbitrators specializing in psychology, mental health, and psychological counseling, in order to judge the validity of the scale questions in the light of the concept and definition of emotional intelligence. Based on the criteria of clarity and the item statements' affiliation with the behavioral area being measured, which specifically deals with the concept of emotional intelligence, the judges expressed several observations regarding the wording of certain paragraphs, which were reformulated, where an $80 \%$ agreement rate was adopted to keep or remove a paragraph.

In order to ascertain the reliability of the scale, Cronbach's Alpha coefficient was used to calculate the internal consistency of the scale. Table 4 shows the reliability coefficient of the emotional intelligence scale in its various dimensions.

Table 4. Reliability Coefficients of the Emotional Intelligence Scale

\begin{tabular}{ll}
\hline Dimension & Reliability coefficient \\
\hline Social skills & 0.81 \\
Self-awareness & 0.85 \\
Self-motivation & 0.87 \\
Emotional regulation & 0.87 \\
Empathy & 0.88 \\
Total & 0.93 \\
\hline
\end{tabular}

Table 4 shows that the reliability coefficients ranged from 0.81 to 0.88 . The total reliability coefficient of the scale was 0.93 , which is an appropriate and sufficient factor for the purposes of the present study.

\subsection{Study Procedures}

To achieve the goals of the study, the following steps were taken:

- Build and prepare the study tools for use and data collection

- Arbitration of the study tools and verification of validity and reliability

- Finalization of the study tools

- Data collection from the study sample

- Data analysis and writing the study report 


\subsection{Statistical Methods}

To answer the first and second study questions, arithmetic means and standard deviations were used. To answer the third study question, regression analysis was used to determine the predictive ability of the dimensions of emotional intelligence in cyberbullying.

\section{Results and Discussion}

The current study aims to identify the predictive power of emotional intelligence on cyberbullying among Jordanian university students. The following is a presentation of the results according to the sequence of study questions.

\subsection{First Question: What is the level of Cyberbullying among Jordanian University Students?}

To answer this question, means and standard deviations were calculated, and the means were arranged accordingly.

Table 5 shows the results.

Table 5. Means and Standard Deviations of Participants' Responses on the Cyberbullying Scale

\begin{tabular}{|c|c|c|c|c|c|}
\hline $\begin{array}{l}\text { Statement } \\
\text { number }\end{array}$ & Statement & Mean & $\begin{array}{l}\text { Standard } \\
\text { deviation }\end{array}$ & Level & Rank \\
\hline 15 & $\begin{array}{l}\text { I think I have the ability to respond to other people's } \\
\text { aggression by spreading rumors about them through social } \\
\text { networks. }\end{array}$ & 2.83 & 1.27 & Moderate & 1 \\
\hline 10 & $\begin{array}{l}\text { I resort to taking revenge on others and embarrassing them } \\
\text { through electronic means when there is conflict between us. }\end{array}$ & 2.79 & 1.25 & Moderate & 2 \\
\hline 17 & $\begin{array}{l}\text { I consider myself capable of using electronic means of } \\
\text { communication to deal with the abuses of others against me. }\end{array}$ & 2.79 & 1.31 & Moderate & 3 \\
\hline 13 & $\begin{array}{l}\text { I feel like I'm in control when I hide behind a fake name and } \\
\text { send emails containing abuse. }\end{array}$ & 2.78 & 1.28 & Moderate & 4 \\
\hline 1 & I post embarrassing comments on my page. & 2.77 & 1.34 & Moderate & 5 \\
\hline 3 & I post embarrassing images on others' pages. & 2.76 & 1.27 & Moderate & 6 \\
\hline 7 & I send emails with offensive information about my friends. & 2.76 & 1.36 & Moderate & 7 \\
\hline 12 & $\begin{array}{l}\text { I feel great relief when I humiliate and abuse other through } \\
\text { electronic means. }\end{array}$ & 2.75 & 1.31 & Moderate & 8 \\
\hline 6 & $\begin{array}{l}\text { I send text messages through email containing insults and } \\
\text { ridicule. }\end{array}$ & 2.73 & 1.33 & Moderate & 9 \\
\hline 14 & $\begin{array}{l}\text { I think the best way to counter other people's aggression is to } \\
\text { use electronic means of communication to respond to them } \\
\text { and mock them. }\end{array}$ & 2.73 & 1.31 & Moderate & 10 \\
\hline 16 & $\begin{array}{l}\text { I feel confident among my friends, because I have the courage } \\
\text { to attack others through electronic means of communication. }\end{array}$ & 2.73 & 1.32 & Moderate & 11 \\
\hline 2 & I hack electronic accounts. & 2.72 & 1.36 & Moderate & 12 \\
\hline 5 & $\begin{array}{l}\text { I send text messages in the form of threats to people I don't } \\
\text { know. }\end{array}$ & 2.72 & 1.29 & Moderate & 13 \\
\hline 4 & I promote news/rumors about myself through text/email. & 2.70 & 1.28 & Moderate & 14 \\
\hline 11 & $\begin{array}{l}\text { I have electronic accounts especially for use in cases where I } \\
\text { need to take revenge. }\end{array}$ & 2.70 & 1.28 & Moderate & 15 \\
\hline 8 & I send short offensive videos to others. & 2.68 & 1.46 & Moderate & 16 \\
\hline \multirow[t]{2}{*}{9} & I make phone calls where I speak to others with contempt. & 2.65 & 1.35 & Moderate & 17 \\
\hline & Average & 2.74 & 1.32 & & \\
\hline
\end{tabular}


Table 5 shows that the means ranged from 2.65 to 2.83 . The highest mean was for the item that states, "I think I have the ability to respond to other people's aggression by spreading rumors about them through social networks", which had a mean of 2.83 with a standard deviation of 1.27 . The lowest mean belonged to the following statement: "I make phone calls where I speak to others with contempt", which had a mean of 2.65 with a standard deviation of 1.35. The general average was 2.74 with a standard deviation of 1.32 , which indicates that the level of cyberbullying was moderate.

The results align with the Barakat study (2009), as they demonstrate the negative effects that emerge from the use of various technological tools and the internet. These effects can be attributed to the lack of proper guidance for university students and the provision of information on the importance of the best use of the internet and other means of communication. This guidance must occur without the use of domestic oppression, violence, or physical abuse. The resulting moderate level of cyberbullying may also be attributed to the lack of family support, specifically in terms of guiding children's behavior and their internet usage habits. The more freedom they have in using the internet, the more likely they are to engage in negative behaviors as a result of being exposed to a variety of harmful things. The lack of family encouragement in exercising self-discipline and practicing self-awareness of their actions while using electronic means of communication in general further contributes to this finding.

The university also has to a role to play by holding seminars to educate caregivers, where the seminars are aimed at helping caregivers guide their children to properly interact with the information network, and the negative effects that may result from its misuse. They should also aim to direct caregivers on how to hold family dialogues and discussions with their children in a calm and balanced manner, and to answer their questions and address their thoughts, attitudes, and the sound or unsound information they might hold in their minds. This role can be carried out by the faculty of social work and the sociology department, specifically regarding working with other social institutions and coordinating with them.

\subsection{Second Question: What is the Level of Emotional Intelligence among Jordanian University Students?}

To answer this question, the means and standard deviations were calculated, and the means were arranged in a descending order. Table 6 shows the results.

Table 6. Means and Standard Deviations of Participants' Responses on the Emotional Intelligence Scale

\begin{tabular}{lllll}
\hline Dimension & Mean & Standard deviation & Level & Rank \\
\hline Social skills & 4.50 & 0.41 & High & 1 \\
Self-awareness & 4.18 & 0.41 & High & 2 \\
Self-motivation & 4.16 & 0.43 & High & 3 \\
Emotional regulation & 4.12 & 0.41 & High & 4 \\
Empathy & 4.10 & 0.40 & High & 5 \\
Overall & 4.13 & 0.37 & High & \\
\hline
\end{tabular}

Table 6 shows that the means ranged from 4.10 to 4.50. The highest mean was for the field of social skills, which was 4.50 with a standard deviation of 0.41 . The lowest mean was for the field of empathy, which was 4.10 with a standard deviation of 0.40 . The general mean was 4.13 with a standard deviation of 0.37 , which indicated that the level of emotional intelligence was high among Jordanian university students.

The high level of emotional intelligence among university students may be due to the nature of the university environment. It is a social environment filled with dialogue and social communication, which provides students with the ability to explore their friends' feelings, to understand the feelings of those around them, to humor their friends and to deal with them calmly, and to build friendships and communicate with others. These are all basic skills and abilities to empathize and communicate with other people. Further, the expectations from university students may prompt them to act in a manner that aligns with those expectations. This may be attributed to the fact that they have a certain level of maturity that enables them to recognize and regulate their emotions, to control their feelings and behaviors, to suppress their negative emotions, to understand and recognize the feelings of others, and to have a good sensitivity to the feelings of others. University students are considered to be an aware and educated social group that is capable of dealing with life's problems, solving them, being resilient, and having control over their emotional regulation. These abilities result from their neuroplasticity, which makes their relationships and actions acceptable and organized in a manner that allows them to feel satisfied with themselves and their lives 
through using emotional regulation methods for achieving their goals.

\subsection{Third Question: Is There a Significant Correlation between Cyberbullying and Emotional Intelligence Dimensions among Jordanian University Students?}

To answer this question, the correlation between cyberbullying and emotional intelligence dimensions among Jordanian university students was calculated. Table 7 shows the results.

Table 7. Pearson's Correlation between Cyberbullying and Emotional Intelligence Dimensions among Jordanian University Students

\begin{tabular}{lll}
\hline Dimension & Correlation coefficient & Significance \\
\hline Self-awareness & $-.391^{* *}$ & 0.001 \\
Emotional regulation & $-.407^{* *}$ & 0.001 \\
Self-motivation & $-.427^{* *}$ & 0.001 \\
Empathy & $-.371^{* *}$ & 0.001 \\
Social skills & $-.365^{* *}$ & 0.001 \\
Overall & $-.428^{* *}$ & 0.001 \\
\hline
\end{tabular}

Table 7 shows that the correlation coefficients between the dimensions of emotional intelligence (self-awareness, emotional regulation, self-motivation, empathy, social skills, and overall level) and cyberbullying had the following values, respectively: $(-0.391,-0.407-,-0.427,-0.371,-0.365,-0.428)$. All of these coefficients are significant at $p=0.05$. Therefore, there is a significant negative correlation between cyberbullying and emotional intelligence dimensions among Jordanian university students.

The negative correlation between cyberbullying and the emotional intelligence of university students can be attributed to a variety of factors, such as the ability to exert self-control, the ability to control emotions in front of others who build a positive image of the student's behavior, as well as the way the student treats others who expect a university student to be smart and mature, and to use his/her brain in dealing with others.

In addition, the university performs the function of linking values to knowledge to develop students' emotional intelligence through indirect guidance and non-traditional education, as values are not established through speech and advice, but through the encouragement of positive attitudes that the university must instill in students.

3.4 Fourth Question: Which Emotional Intelligence Dimensions are the Most Predictive of Cyberbullying among Jordanian University Students?

To answer this question, a stepwise multiple regression analysis was performed, and the results are displayed in Table 8 .

Table 8. Results of the Stepwise Multiple Regression Analysis of the Most Predictive Emotional Intelligence Dimensions of Cyberbullying among Jordanian University Students

\begin{tabular}{llllllll}
\hline & Correlation & Constant values & $\boldsymbol{F}$-value & Significance & Beta & $\boldsymbol{t}$-value & Significance \\
\hline Self-motivation & 0.43 & 0.18 & 98.73 & 0.00 & -.284 & -3.916 & .000 \\
Emotional regulation & 0.44 & 0.19 & 5.93 & 0.02 & -.177 & -2.435 & .015 \\
\hline
\end{tabular}

Table 8 shows that the correlation coefficient between the self-motivation variable as one of the dimensions of emotional intelligence and cyberbullying was 0.43 . The statistical value was 98.73 at a significance level of $p=$ 0.05 , and the beta coefficient was -0.284 , which indicates that self-motivation negatively predicts cyberbullying, and that self-motivation accounted for $18 \%$ of the degree of cyberbullying. The results also showed that emotional regulation explained only $1 \%$ more than what was explained by self-motivation, and the beta coefficient was -0.177 . This shows an inverse relationship, indicating that emotional regulation negatively predicts cyberbullying.

University students tend to have high self-esteem and self-assertion levels, as they achieve harmony within themselves and their environments with the help of those around them. This provides a suitable atmosphere that meets their needs and helps them achieve security, peace, and harmony. At this stage in their lives, university 
students have many psychological pressures that can lead to lower motivation and higher self-dissatisfaction, stress, psychological conflicts, as well as an inability to meet basic psychological needs that are based on self-worth and the deterioration of their internal feelings. Consequently, they are unable to achieve their goals; in particular, their educational goals, as a result of not taking advantage of their skills and abilities for overcoming challenges.

As for university students who have the ability to monitor and manage their emotions, while taking into account the nature of university relations and avoiding the problems that stem from lack of emotional control, in addition to the nature of the experiences that are acquired during their studies and to the characteristics associated with the post-secondary level, these abilities increase their life experience and help them solve the problems that they face without resorting to cyberbullying. This means that the emotional side of the personality is meant to facilitate emotional control when faced with dangerous or difficult situations.

\section{Conclusions and Implications}

The goal of the present study was to examine the predictive ability of emotional intelligence dimensions on cyberbullying behaviors among Jordanian university students. Results indicated that emotional intelligence in all its secondary dimensions (self-awareness, emotional regulation, self-motivation, empathy, and social skills) negatively predicts cyberbullying behaviors among students. These findings have implications that should be taken into consideration in the development of interventional, educational, and preventative programs that address cyberbullying behaviors. Programs that support an understanding and development of emotional intelligence skills such as emotional regulation, self-awareness, empathy...etc. may prove to be particularly effective in changing bullying behavioral patterns among student populations.

\section{References}

Al-Masri, N. (2011). University student use of social media sites and its impact on other media usage: a study of a sample of Palestinian college students. Paper presented at the Media College conference at Yarmouk University entitled "Media and Societal Transformations in the Arab World", held from November 23-25, 2011, Yarmouk University, Irbid, Jordan.

Ateya, H. M. (2007). An experiment in the ethics of the information society: a survey of students' views of information science. Arabic Library and Information Journal, 27(3).

Backe, E. L., Lilleston, P., \& McCleary-Sills, J. (2018). Networked Individuals, Gendered Violence: A Literature Review of Cyberviolence. Violence and Gender, 5(3), 135-146. https://doi.org/10.1089/vio.2017.0056

Bakir, A. (2010). Evolution of the role of the university in the service of society in the light of community responsibility and modern global trends. Paper presented at the conference of Social Responsibility for Palestinian Universities, Yarmouk University, Irbid, Jordan. Abstract retrieved from https://arabci.org/Articles?id=30560

Barakat, F. (2009). The various negative effects of modern means of communication on social upbringing. Paper presented at the Educational Psychological Conference, the Faculty of Education, the University of Damascus, Damascus, Syria. Abstract retrieved from https://socio.yoo7.com/t3523-topic

Extremera, N., Quintana-Orts, C., Mérida-López, S., \& Rey, L. (2018). Cyberbullying victimization, self-esteem and suicidal ideation in adolescence: Does emotional intelligence play a buffering role? Frontiers in Psychology, 9, 367. https://doi.org/10.3389/FPSYG.2018.00367/BIBTEX

Fonseca, L., \& Nieth, L. (2021). The role of universities in regional development strategies: A comparison across actors and policy stages. European Urban and Regional Studies, 28(3), 298-315. https://doi.org/10.1177/0969776421999743

Golubev, V. (2003) Criminals in computer related crimes. Retrieved January 1, 2022, from https://www.crime-research.org/articles/Golubev_nov1

Holdren, A. (2020). Examining the impact of adolescent cyberbullying on early adulthood self-esteem and self-efficacy (Doctoral Dissertation). Available from ProQuest Dissertation \& Theses.

Jarrar, L. A. (2011). Facebook participation and its relationship to Jordanian university students'attitudes towards family relations (Unpublished master's thesis). Middle East University, Amman, Jordan.

Martínez-Monteagudo, M. C., Delgado, B., Inglés, C. J., \& García-Fernández, J. M. (2019). Cyberbullying in the university setting. Relationship with family environment and emotional intelligence. Computers in Human Behavior, 91, 220-225. https://doi.org/10.1016/J.CHB.2018.10.002 
Mayer, J. D. \& Salovey, P. (1997). What is Emotional Intelligence? In P. Salovey \& D. Sluyter (Eds). Emotional Development and Emotional Intelligence: Implications for Educators (pp. 3-31). New York: Basic Books.

Nejadat, A. A (2014). The uses of married working women in Jordanian universities for Facebook and achieved satisfactions: a survey study. Jordanian Journal of Social Sciences, 7(1).

Novo, F., Pereira, F., \& Matos, M. (2014). Cyber-aggression among Portuguese adolescents' cyber-aggression among Portuguese adolescents: a study on perpetration, victim offender overlap and parental supervision. International Journal of Cyber Criminology, 8(2), 94-110. https://doi.org/10.1016/j.childyouth.2018.06.021

Pfeiffer, S. I. (2010). Emotional intelligence: popular but elusive construct. Roeper Review, 23(3), 138-142, https://doi.org/10.1080/02783190109554085

Sebti, A. (2013). What is bullying and cyber violence? Retrieved from https://www.minshawi.com/?q=content/ ما_هو _العنف_أو -التسلط_عبر -الانترنت_.

Sebti, A. (2014). Bullying and cyber violence. Retrieved from http://sabti2014.blogspot.com/2014/02/1.html

Trigueros, R., Padilla, A. M., Aguilar-Parra, J. M., Rocamora, P., Morales-Gázquez, M. J., \& López-Liria, R. (2020). The influence of emotional intelligence on resilience, test anxiety, academic stress and the Mediterranean diet: a study with university students. International Journal of Environmental Research and Public Health, 17(6), 2071. https://doi.org/10.3390/IJERPH17062071

Vale, A., Pereira, F., Gonçalves, M., \& Matos, M. (2018). Cyber-aggression in adolescence and internet parenting styles: A study with victims, perpetrators and victim-perpetrators. Children and Youth Services Review, 93, 88-99. https://doi.org/10.1016/J.CHILDYOUTH.2018.06.021

Yadav, M., \& Yadav, R. (2018). Impact of spirituality/religiousness on cyber bullying and victimization in university students: mediating effect of emotional intelligence. Journal of Religion and Health, 57(5), 1961-1979. https://doi.org/10.1007/S10943-018-0637-8

\section{Copyrights}

Copyright for this article is retained by the author(s), with first publication rights granted to the journal.

This is an open-access article distributed under the terms and conditions of the Creative Commons Attribution license (http://creativecommons.org/licenses/by/4.0/). 